\title{
Intramolecular Cyclizations of $\alpha$-Stannyl Radicals to Acylsilanes: Regiospecific Syntheses of Five-membered Cyclic Silyl Enol Ethers
}

\author{
Yeun-Min Tsai* and Sheng-Yueh Chang \\ Department of Chemistry, National Taiwan University, Taipei, Taiwan 106, Republic of China
}

$\alpha$-Stannyl radicals generated from acylsilanes 5, 13 and 14 cyclize to give good yields of cyclic silyl enol ethers after sequential cyclizations, radical Brook rearrangements and $\beta$-scissions.

Acylsilanes have gained more and more attention in recent years. ${ }^{1}$ Radical cyclization reactions of acylsilanes involve the formation of $\beta$-silyl alkoxy radicals 1 which quickly rearrange to give $\alpha$-silyloxy radicals $2 .^{2}$ This special feature creates opportunities for further elaboration. ${ }^{3}$ Here we report the use of $\alpha$-stannyl radicals to cyclize with acylsilanes and give cyclic silyl enol ethers in a regiospecific way.

Aldehydes $3^{3 a}$ were treated with tributyltin anions and the resulting $\alpha$-stannyl alcohols were converted to $\alpha$-stannyl bromides 4 using triphenylphosphine and tetrabromomethane (Scheme 1). Hydrolysis of $\mathbf{4}$ with ceric ammonium nitrate $(\mathrm{CAN})^{4}$ gave acylsilanes $\mathbf{5}$ in moderate yields over the three steps.

Cyclizations of 5 in refluxing benzene with slow addition of a catalytic amount of tributyltin hydride ( 0.15 equiv.) and AIBN ( 0.05 equiv.) gave silyl enol ethers 6 (Scheme 2$). \dagger$ The presence of 6 was confirmed by comparing their crude ${ }^{1} \mathrm{H}$ NMR spectra with those of the authentic samples prepared from cyclopentanone. However, the crude products of 6 were converted to the 2,4-dinitrophenylhydrazone of cyclopentanone to estimate the yields of the cyclizations. In the cases of $\mathbf{6 a}, \mathbf{c}$ and $\mathbf{d}$, the overall conversion yields were very good. The low yield in the case with a bulky tert-butyldimethylsilyl group $\mathbf{6 b}$ indicated that the cyclization was not efficient. This may attributable to the steric interactions between the silyl group and the tributylstannyl group. The whole process invovles the generation of $\alpha$-stannyl radicals 8 which cyclize to give radicals 9 . These radicals undergo radical Brook rearrangements ${ }^{5}$ to give radicals $\mathbf{1 0}$ which are set up to perform facile $\beta$-scissions and give silyl enol ethers 6 with concomitant formation of a tributyltin radical. The tin radical then abstracts the bromine atom from 5 to regenerate radicals $\mathbf{8}$, thus completes the cycle.
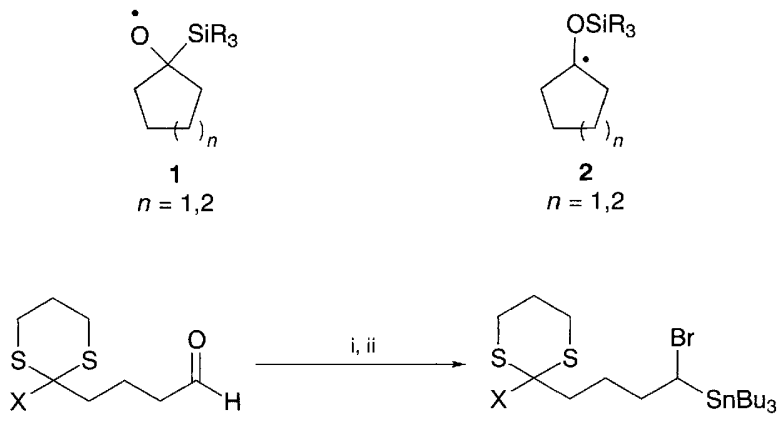

a $\mathrm{X}=\mathrm{Me}_{3} \mathrm{Si}$

b $\mathrm{X}=\mathrm{Bu}^{\mathrm{t} M \mathrm{Me}_{2} \mathrm{Si}}$

c $\mathrm{X}=\mathrm{Me}_{2} \mathrm{PhSi}$

d $\mathrm{X}=\mathrm{MePh}_{2} \mathrm{Si}$

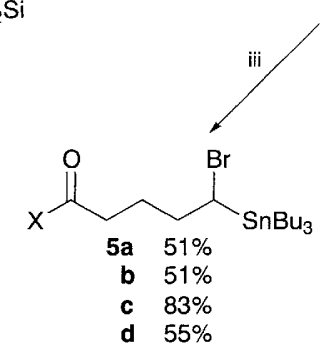

4 a $71 \%$

d $41 \%$

c $57 \%$

d $64 \%$
To demonstrate the regiospecific nature of this approach for the preparation of cyclic silyl enol ethers, we intended to synthesize bromides 11 and $\mathbf{1 2}$. However, the same route used for the synthesis of $\mathbf{5}$ gave low yields in these cases. This was probably due to the instability of the structures of type 4 in which a nucleophile and an electrophile coexist. ${ }^{6}$ Therefore, a different route was developed. Alkylation of the 2-silyl1,3-dithiane 15 with 2-(3-bromo-1-methylpropyl)-1,3-dioxolane $^{7}$ gave 16 in $83 \%$ yield (Scheme 3 ). The aldehyde 17 obtained from hydrolysis of $\mathbf{1 6}$ was treated with tributyltin lithium, and the resulting alkoxide was trapped sequentially with carbon disulfide and methyl iodide to construct the xanthate moiety. The dithiane was then hydrolysed with

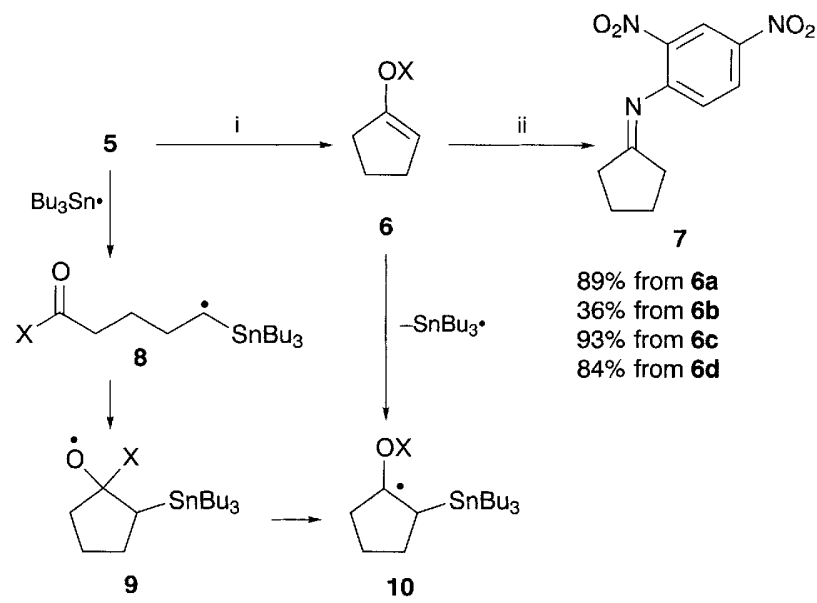

Scheme 2 Reagents and Conditions: $\mathrm{i}, \mathrm{Bu} 3 \mathrm{SnH}(0.15$ equiv.), AIBN $(0.05$ equiv.), $\mathrm{C}_{6} \mathrm{H}_{6}, 80^{\circ} \mathrm{C}$; ii, 2,4-dinitrophenylhydrazine, $\mathrm{H}^{+}, \mathrm{EtOH}$
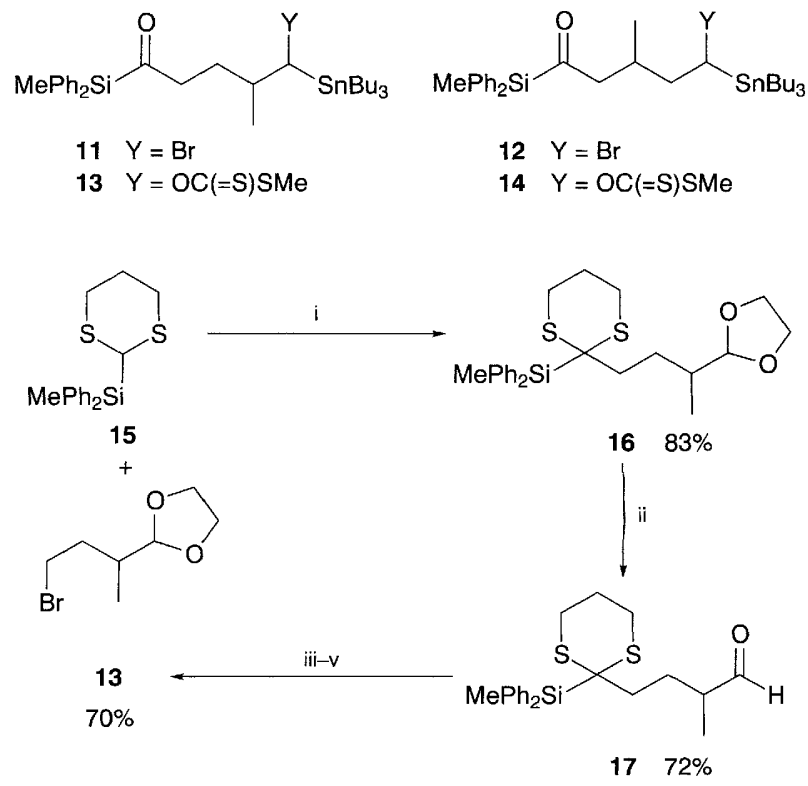

Scheme 3 Reagents: i, BuLi; ii, p-Me- $\mathrm{C}_{6} \mathrm{H}_{4} \mathrm{SO}_{3} \mathrm{H}$ (cat.), $\mathrm{H}_{2} \mathrm{O}$, THF; iii, $\mathrm{Bu}_{3} \mathrm{SnLi}$; iv, $\mathrm{CS}_{2}$, MeI; v, $\left(\mathrm{CF}_{3} \mathrm{CO}_{2}\right)_{2} \mathrm{IC}_{6} \mathrm{H}_{5}, \mathrm{H}_{2} \mathrm{O}, \mathrm{MeCN}, \mathrm{THF}, \mathrm{NaHCO}_{3}$ 
iodobenzene bis(trifluoroacetate) to give $\mathbf{1 3}$ in $70 \%$ yield from the aldehyde. ${ }^{8}$ The xanthate $\mathbf{1 4}$ was synthesized accordingly in similar yields.

Radical cyclizations of $\mathbf{1 3}$ and $\mathbf{1 4}$ under the same conditions as stated above gave the two regioisomeric silyl ethers 18 and 19, respectively. To confirm the structures, the crude products were treated with phenylselenyl bromide in dichloromethane at $-78^{\circ} \mathrm{C}$. The selenide $\mathbf{2 0}$ was obtained in $68 \%$ yield from $\mathbf{1 3}$ as a mixture of cis/trans $(1: 2)$ isomers. ${ }^{9}$ The selenide 21 was obtained in $77 \%$ yield from 14 as an $8.8: 1$ mixture of two stereoisomers. $\ddagger$

Attempted radical cyclization of $\mathbf{2 2}$ initiated with tributyltin hydride ( 0.15 equiv.) and AIBN ( 0.05 equiv.) was not successful. Only the reduction product $\mathbf{2 3}$ was observed along with mostly unreacted 22. With a full equivalent of tributyltin hydride, the acylsilane $\mathbf{2 3}$ was isolated in $80 \%$ yield. It has been reported for radical cyclizations of acylsilanes that 1,5-hydrogen atom transfer was a competing process with 1,6-cyclization. ${ }^{3 a}$ In the case of $\mathbf{2 2}$, the unfavourable interactions between the silyl and stannyl groups probably blocked the cyclization completely.

In summary, the radical cyclizations described herein represent a novel regiospecific approach to the syntheses of five-membered cyclic silyl enol ethers. This report also demonstrates that $\alpha$-stannyl radicals can be very useful if

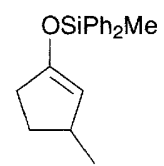

18

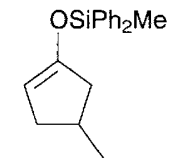

19

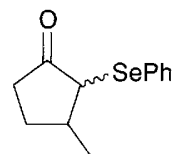

20

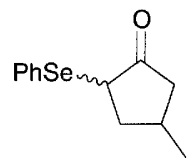

21

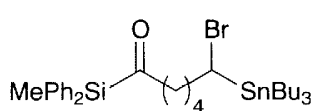

22

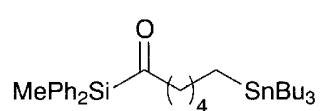

23 properly designed. The potential of $\alpha$-stannyl radicals is currently under investigations.

We thank the National Science Council of the Republic of China for financial support (Grants 83-0208-M-002-042 and 84-2113-M-002-006).

Received, 13th February 1995; Com. 5/00841G

\section{Footnotes}

$\uparrow$ Typical procedure: Tributyltin hydride $(21 \mu 1,0.078 \mathrm{mmol})$ and AIBN $(5 \mathrm{mg}, 0.03 \mathrm{mmol}$ ) in benzene $(5 \mathrm{ml})$ were added over $1 \mathrm{~h}$ to a solution of $5 \mathrm{c}$ ( $295 \mathrm{mg}, 0.503 \mathrm{mmol}$ ) in benzene $(5 \mathrm{ml})$ heated at $80^{\circ} \mathrm{C}$. The resulting solution was heated for a further hour and then concentrated in vacuo to obtain the crude product which was used directly in the subsequent reaction.

\$ The major isomer was presumably the trans isomer; however, the stereochemistry was not determined. The characteristic ${ }^{1} \mathrm{H}$ NMR $\left(400 \mathrm{MHz}, \mathrm{CDCl}_{3}\right)$ signal for the major isomer appears at $\delta 3.82(\mathrm{br} \mathrm{d}, J$ $6.6 \mathrm{~Hz}$ ), and that of the minor one appears at 3.72 (br dd, $J 11,8.4 \mathrm{~Hz}$ ).

\section{References}

1 A. Ricci and A. Degl'Innocenti, Synthesis, 1989, 647; P. C. B. Page, S. S. Klair and S. Rosenthal, Chem. Soc. Rev., 1990, 19, 147; P. F. Cirillo and J. S. Panek, Org. Rep. Procedure Int., 1992, 24, 553.

2 Y.-M. Tsai and C.-D. Cherng, Tetrahedron Lett., 1991, 32, 3515.

3 (a) Y.-M. Tsai, K.-H. Tang and W.-T. Jiaang, Tetrahedron Lett., 1993, 34, 1303; (b) D. P. Curran, W.-T. Jiaang, M. Palovich and Y.-M. Tsai, Syn. Lett., 1993, 403

4 T.-L. Ho, H. C. Ho and C. M. Wong, J. Chem. Soc., Chem. Commun., 1972, 791; H.-J. Cristau, B. Chabaud, R. Labaudinière and H. Christol, Synth. Commun., 1981, 11, 423.

5 J. C. Dalton and R. A. Borque, J. Am. Chem. Soc., 1981, 103, 699; J. M. Harris, I. MacInnes, J. C. Walton and B. Maillard, J. Organomet. Chem., 1991, 403, C25.

6 A. E. Davey, A. F. Parsons and R. J. K. Taylor, J. Chem. Soc., Perkin Trans. 1, 1989, 1853; Z. Sui, P. S. Furth and J. J. De Voss, J. Org. Chem., $1992,57,6658$.

7 D. J. Collins and A. M. James, Aust. J. Chem., 1989, 42, 223.

8 G. Stork and K. Zhao, Tetrahedron Lett., 1989, 30, 287.

9 T. Toru, T. Okumura and Y. Ueno, J. Org. Chem., 1990, 55, 1277. 